\title{
Association between educational level and health related quality of life in Spanish adults
}

\author{
Enrique Regidor, Gregorio Barrio, Luis de la Fuente, Antonia Domingo, \\ Carmen Rodriguez, Jordi Alonso
}

\begin{abstract}
Objective-To analyse differences in health by educational level in Spanish adults by comparing the health dimensions of the SF-36 Heath Survey.

Design-Data were taken from the National Survey on Drug Use carried out in February 1996. The information was collected by home personal interview. In addition to measuring the use of legal and illegal drugs and their associated health risks, the health status of the Spanish population was analysed using the Spanish version of the SF-36 Health Survey.

Main outcome measure-Absolute and standardised differences between mean score on each dimension of the SF-36 Health Survey in each educational group with respect to the group with the highest educational level.

Results-Perceived health status declines with decreasing educational level, except in women with second level education who have a higher mean rating than women with third level education on various health dimensions. The absolute differences in perceived health between the different categories of educational level and the reference category become larger with increasing age. The greatest differences by educational level in both men and women were found in mental health and general health among persons 25 to 44 years of age, and in physical function and general health among those 45 to 64 years. In persons aged 65 or older, the greatest differences are seen in physical function and vitality in men, and in bodily pain and emotional role in women.
\end{abstract}

Conclusions-The influence of educational level on the different dimensions of perceived health may vary by sex.

(f Epidemiol Community Health 1999;53:75-82)

One of the most consistent observations in the history of public health research is the finding of an inverse relation between socioeconomic level and health, according to which persons in lower socioeconomic strata have higher mortality and more frequent health problems than those in higher socioeconomic strata. ${ }^{1-6}$ This association has been found for all indicators of socioeconomic level, whether they are based on occupation, education or income.

Unfortunately, despite its importance, this characteristic of people remains little understood and it is not known exactly how it operates. Syme has pointed out that one reason for this lack of understanding is based on the use of an inappropriate disease classification scheme: although the classification used is very useful for treating diseases, it is inadequate both for aetiological research and for prevention and implementation of specific health policies. $^{7}$ This author has recently noted that, whereas we pay a great deal of attention to disease occurrence and disease related death, we ignore such an extraordinarily important aspect as quality of life. ${ }^{8}$ Syme uses the example of life expectancy in men and women. Although life expectancy is much greater in women than in men, when we adjust for the ability to bathe, dress, and feed oneself and to move independently from bed to chair, the female advantage disappears.

The measures of health related quality of life were developed to evaluate the effectiveness of health services, however some of them-such as the Nottingham Health Profile, ${ }^{9}$ the Sickness Impact Profile ${ }^{10}$ or the SF- $36^{11}$-have been used in population based studies. These quality of life measures are of interest mainly because they overcome the limitations of morbidity and mortality information in evaluating the impact of particular social, economic or health interventions on a wide array of health dimensions such as physical mobility, social function, emotional well being, mental health, and general well being. It has recently been proposed that public health surveillance systems incorporate measures of health related quality of life as a way to evaluate the health status of the population. ${ }^{12}$

Although in recent years there has been increasing evidence of differences in the frequency of health problems among different socioeconomic groups, rarely have differences in health related quality of life been shown among these groups, as Syme has noted. In this study we have evaluated the socioeconomic differences in health in Spanish adults by measuring different health dimensions with the SF-36 Health Survey, using educational level as an indicator of socioeconomic position. We rejected the use of social class based on occupation because the study would then have been limited almost exclusively to employed men because of the high rate of unemployment among Spanish adults and the low rate of employment among Spanish women ${ }^{13}$; educational level, on the other hand, is a variable that can be applied to the entire population. ${ }^{14}$

\section{Methods}

DATA SOURCE

This study was based on information taken from the National Survey on Drug Use carried 
Table 1 Number of men and women analysed, by age and educational level

\begin{tabular}{|c|c|c|c|c|c|c|}
\hline \multirow[b]{2}{*}{ Educational level } & \multicolumn{3}{|l|}{ Men } & \multicolumn{3}{|l|}{ Women } \\
\hline & $25-44$ & $45-65$ & $\geqslant 65$ & $25-44$ & $45-65$ & $\geqslant 65$ \\
\hline Total & 1724 & 1174 & 827 & 1724 & 1311 & 1063 \\
\hline Third level & 359 & 151 & 54 & 345 & 85 & 21 \\
\hline Second level & 952 & 371 & 121 & 935 & 337 & 107 \\
\hline First level & 298 & 347 & 243 & 303 & 446 & 261 \\
\hline No education completed & 115 & 305 & 409 & 141 & 443 & 674 \\
\hline
\end{tabular}

out within the framework of the National Plan on Drugs, the field work for which was conducted in February 1996. The sampling universe was the non-institutionalised population aged 15 years or older residing in Spain. The information was collected by personal interview in the residence of the persons interviewed. Before measuring the use of legal and illegal drugs and the perceived risks associated with them, the health status of the Spanish population was evaluated using the Spanish version of the SF-36 Health Survey. ${ }^{15} 16$

The sample size was 9984 persons. A multistage stratified sampling procedure was used. The first stage units (census sections) were randomly selected, after stratifying by region and size of municipality of residence. Then, within each census section the buildings and homes to be sampled were selected using the procedure of random routes. Finally, the last stage sampling units-the individuals - were selected randomly from all persons living in the same household.

As the survey was also intended to measure illicit drug use, which is mainly concentrated in the 15-39 year age group, it was decided to over-represent this group in the sample. Therefore for each person over 39 years of age three persons 15-39 years of age were selected. The proportionality of the sample was then restored by assigning each person selected a weighting coefficient in function of the age group, sex, and region of residence. Some $19.9 \%$ of the interviews were made after one or more previously selected people refused to answer the questionnaire or could not be located after three visits to the household. In the sample finally interviewed the percentage of people with no education completed $(22 \%)$

Table 2 Mean (SEM) ratings on the SF-36 Health Questionnaire for the whole population of men and for men with third level education and absolute differences in mean range (95\% CI) in the other groups with respect to the reference groupt

\begin{tabular}{|c|c|c|c|}
\hline & \multicolumn{3}{|l|}{ Age } \\
\hline & $25-44$ & $45-65$ & $\geqslant 65$ \\
\hline \multicolumn{4}{|l|}{ Physical functioning } \\
\hline Whole population & $96.0(0.3)$ & $86.5(0.6)$ & $65.8(1.0)$ \\
\hline Third level & $97.7(0.4)$ & $93.4(1.1)$ & $86.3(2.2)$ \\
\hline Second level & $-2.2(-4.0,-0.4)^{\star}$ & $-2.6(-7.4,2.0)$ & $-11.2(-21.7,-0.6)^{\star}$ \\
\hline First level & $-1.2(-3.5,-1.0)$ & $-9.0(-13.7,-4.2)^{\star}$ & $-19.8(-29.5,-10.0)^{\star}$ \\
\hline No education completed & $-3.0(-6.1,0.1)$ & $-13.1(-17.9,-8.2)^{\star}$ & $-26.6(-35.9,-17.2)^{\star}$ \\
\hline \multicolumn{4}{|l|}{ Role physical } \\
\hline Whole population & $92.5(0.6)$ & $84.0(1.0)$ & $75.8(1.4)$ \\
\hline Third level & $95.1(1.0)$ & $94.0(1.5)$ & $95.5(2.2)$ \\
\hline Second level & $-3.2(-6.9,0.5)$ & $-4.4(-12.2,3.3)$ & $-4.6(-20.1,10.8)$ \\
\hline First level & $-2.4(-7.1,2.2)$ & $-11.9(-19.8,-4.0)^{\star}$ & $-19.3(-33.5,-5.0)^{\star}$ \\
\hline No education completed & $-5.6(-12.0,0.8)$ & $-19.6(-27.6,-11.6)^{\star}$ & $-27.1(-40.8,-13.4)^{\star}$ \\
\hline \multicolumn{4}{|l|}{ Bodily pain } \\
\hline Whole population & $88.5(0.5)$ & $79.9(0.8$ & $76.8(1.0)$ \\
\hline Third level & $90.2(1.0)$ & $89.0(1.5)$ & $92.6(1.7)$ \\
\hline Second level & $-2.0(-5.1,1.0)$ & $-5.8(-12.2,0.5)$ & $-10.7(-21.6,0.2)$ \\
\hline First level & $-1.5(-5.4,2.4)$ & $-10.1(-16.0,-6.2)^{\star}$ & $-15.0(-25.1,-4.9)^{\star}$ \\
\hline No education completed & $-4.4(-9.7,1.0)$ & $-16.4(-22.9,-9.8)^{\star}$ & $-19.9(-29.6,-10.2)^{\star}$ \\
\hline \multicolumn{4}{|l|}{ General health } \\
\hline Whole population & $76.7(0.4)$ & $67.4(0.6)$ & $55.2(0.8)$ \\
\hline Third level & $80.7(0.8)$ & $74.8(1.4)$ & $66.7(2.5)$ \\
\hline Second level & $-4.4(-7.0,-1.7)^{\star}$ & $-0.7(-5.6,4.1)$ & $-1.0(-23.9,-8.3)$ \\
\hline First level & $-5.7(-9.0,-2.3)^{\star}$ & $-11.1(-16.0,-6.2)^{\star}$ & $-11.2(-19.4,-3.1)^{\star}$ \\
\hline No education completed & $-9.1(-13.7,-4.5)^{\star}$ & $-15.0(-20.0,-10.0)^{\star}$ & $-16.2(-9.3,7.9)^{\star}$ \\
\hline \multicolumn{4}{|l|}{ Vitality } \\
\hline Whole population & $74.1(0.4)$ & $69.1(0.7)$ & $60.0(0.8)$ \\
\hline Third level & $76.2(0.8)$ & $74.8(1.4)$ & $76.2(2.0)$ \\
\hline Second level & $-2.7(-5.3,-0.0)^{\star}$ & $-2.8(-8.1,2.5)$ & $-7.5(-16.5,1.4)$ \\
\hline First level & $-1.3(-4.7,2.0)$ & $-7.7(-13.0,-2.2)^{\star}$ & $-14.3(-22.5,-6.0)^{\star}$ \\
\hline No education completed & $-5.5(-10.1,-0.9)^{\star}$ & $-10.0(-15.5,4.5)^{\star}$ & $-22.0(-29.9,-14.0)^{\star}$ \\
\hline \multicolumn{4}{|l|}{ Social functioning } \\
\hline Whole population & $95.4(0.3)$ & $91.8(0.5)$ & $84.7(0.9)$ \\
\hline Third level & $96.2(0.6)$ & $95.4(1.0)$ & $96.4(1.0)$ \\
\hline Second level & $-0.9(-2.8,1.0)$ & $-0.7(-4.8,3.5)$ & $-5.9(-15.4,3.7)$ \\
\hline First level & $-0.8(-3.3,1.6)$ & $-3.5(-7.7,0.7)$ & $-10.1(-18.9,-1.2)^{\star}$ \\
\hline No education completed & $-2.3(-5.6,1.0)$ & $-9.0(-13.3,-4.6)^{\star}$ & $-16.0(24.5,-7.5)^{\star}$ \\
\hline \multicolumn{4}{|l|}{ Role emotional } \\
\hline Whole population & $95.2(0.6)$ & $93.1(0.7)$ & $87.6(1.1)$ \\
\hline Third level & $97.3(0.8)$ & $98.1(0.7)$ & $100.0(0.0)$ \\
\hline Second level & $-3.0(-5.8,-0.1)^{\star}$ & $-2.3(-7.8,3.5)$ & $-4.6(-16.8,7.7)$ \\
\hline First level & $-0.7(-4.3,2.9)$ & $-4.6(-10.2,1.1)$ & $-14.0(-25.3,-2.7)^{\star}$ \\
\hline No education completed & $-5.2(-10.0,-0.3)^{\star}$ & $-11.1(-16.9,-5.3)^{\star}$ & $-15.3(-16.8,-7.7)^{\star}$ \\
\hline \multicolumn{4}{|l|}{ Mental health } \\
\hline Whole population & $77.8(0.4)$ & $76.8(0.6)$ & $73.6(0.7)$ \\
\hline Third level & $80.6(0.8)$ & $82.3(1.3)$ & $86.2(1.9)$ \\
\hline Second level & $-3.0(-5.5,-0.4)^{\star}$ & $-3.0(-7.4,1.5)$ & $-8.9(-17.2,-0.6)^{\star}$ \\
\hline First level & $-3.0(-6.2,0.2)$ & $-5.5(-9.9,-0.9)^{\star}$ & $-11.2(-18.8,-3.5)^{\star}$ \\
\hline No education completed & $-9.5(-13.9,-5.1)^{\star}$ & $-11.1(-15.7,-6.4)^{\star}$ & $-16.2(-23.5,-8.8)^{\star}$ \\
\hline
\end{tabular}

† Difference between the mean rating at each educational level and the rating of the group with the third level education. ${ }^{\star}$ Statistically significant difference $(\mathrm{p}<0.05)$. 
Table 3 Mean (SEM) ratings on the SF-36 Health Questionnaire for the whole population of women and for women with third level education and absolute differences in mean range (95\% CI) in the other groups with respect to the reference groupt

\begin{tabular}{|c|c|c|c|}
\hline & \multicolumn{3}{|l|}{ Age } \\
\hline & $25-44$ & $45-65$ & $\geqslant 65$ \\
\hline \multicolumn{4}{|l|}{ Physical functioning } \\
\hline Whole population & $93.4(0.3)$ & $78.8(0.6)$ & $55.8(0.9)$ \\
\hline Third level & $94.0(0.8)$ & $89.4(1.7)$ & $68.3(3.7)$ \\
\hline Second level & $0.6(-1.5,2.7)$ & $-3.4(-10.0,3.1)$ & $-2.9(-18.9,13.2)$ \\
\hline First level & $-2.7(-5.4,-0.1)^{\star}$ & $-8.8,(-15.2,-2.3)^{\star}$ & $-7.0(-22.2,8.3)$ \\
\hline No education completed & $-4.7(-8.1,-1.3)^{\star}$ & $-19.6(-26.0,-13.2)^{\star}$ & $-16.6(-31.5,-1.6)^{\star}$ \\
\hline \multicolumn{4}{|l|}{ Role physical } \\
\hline Whole population & $87.5(0.7)$ & $77.4(1.1)$ & $60.5(1.4)$ \\
\hline Third level & $87.3(1.6)$ & $86.6(3.5)$ & $85.8(4.6)$ \\
\hline Second level & $1.5(-3.2,6.2)$ & $-5.3(-16.5,5.9)$ & $-20.3(-46.4,5.8)$ \\
\hline First level & $-2.8(-8.6,3.1)$ & $-7.7(-18.6,3.3)$ & $-22.8(-47.6,2.0)$ \\
\hline No education completed & $-1.4(-8.9,6.1)$ & $-15.8(-26.8,-4.7)^{\star}$ & $-27.8(-52.1,-3.6)^{\star}$ \\
\hline \multicolumn{4}{|l|}{ Bodily pain } \\
\hline Whole population & $82.3(0.6)$ & $70.0(0.9)$ & $59.5(1.0)$ \\
\hline Third level & $84.2(1.2)$ & $76.4(3.1)$ & $79.4(5.0)$ \\
\hline Second level & $-1.0(-4.8,2.7)$ & $0.7(-8.2,9.5)$ & $-11.4(-29.7,6.8)$ \\
\hline First level & $-5.1(-9.8,-0.3)^{\star}$ & $-7.1(-15.7,1.6)$ & $-20.9(-38.3,-3.5)^{\star}$ \\
\hline No education completed & $-6.1(-12.2,-0.1)^{\star}$ & $-12.1(-20.8,-3.5)^{\star}$ & $-21.4(-38.4,-4.4)^{\star}$ \\
\hline \multicolumn{4}{|l|}{ General health } \\
\hline Whole population & $74.5(0.4)$ & $62.3(0.6)$ & $49.1(0.7)$ \\
\hline Third level & $77.5(0.9)$ & $70.1(1.7)$ & $55.3(3.5)$ \\
\hline Second level & $-2.0(-4.6,0.6)$ & $0.0(-6.2,6.3)$ & $2.8(-10.2,15.9)$ \\
\hline First level & $-7.2(-10.5,-3.9)^{\star}$ & $-8.1(-14.2,-1.9)^{\star}$ & $-3.9(-16.3,8.4)$ \\
\hline No education completed & $-7.9(-12.0,-3.7)^{\star}$ & $-15.0(-21.1,-8.8)^{\star}$ & $-8.7(-20.8,-3.4)$ \\
\hline \multicolumn{4}{|l|}{ Vitality } \\
\hline Whole population & $69.1(0.5)$ & $61.9(0.6)$ & $52.0(0.7)$ \\
\hline Third level & $71.9(1.0)$ & $65.0(2.4)$ & $59.5(3.5)$ \\
\hline Second level & $-2.6(-5.7,0.4)$ & $2.1(-4.5,8.6)$ & $-2.6(-15.8,10.5)$ \\
\hline First level & $-6.4(-10.2,-2.5)^{\star}$ & $-2.7(-9.1,3.7)$ & $-6.2(-18.8,6.3)$ \\
\hline No education completed & $-3.3(-8.2,1.5)$ & $-8.0(-14.5,-1.5)^{\star}$ & $-9.0(-15.8,10.6)$ \\
\hline \multicolumn{4}{|l|}{ Social functioning } \\
\hline Whole population & $92.4(0.4)$ & $87.5(0.6)$ & $78.1(0.8)$ \\
\hline Third level & $92.9(0.9)$ & $91.9(2.1)$ & $89.3(4.0)$ \\
\hline Second level & $0.4(-2.2,2.9)$ & $-3.1(-9.6,3.4)$ & $-7.4(-22.8,8.1)$ \\
\hline First level & $-2.6(-5.7,0.6)$ & $-3.9(-10.3,2.4)$ & $-10.6(-25.3,4.0)$ \\
\hline No education completed & $-2.9(-6.9,1.1)$ & $-6.8(-13.1,-0.4)^{\star}$ & $-12.4(-26.7,1.9)$ \\
\hline \multicolumn{4}{|l|}{ Role emotional } \\
\hline Whole population & $89.7(0.7)$ & $83.2(1.0)$ & $74.3(1.3)$ \\
\hline Third level & $92.6(1.3)$ & $92.9(2.3)$ & $100.0(0.0)$ \\
\hline Second level & $-2.6(-6.9,1.7)$ & $-6.5(-16.7,3.7)$ & $-20.4(-44.4,3.5)$ \\
\hline First level & $-6.3(-11.7,-0.9)^{\star}$ & $-8.7(-18.7,1.2)$ & $-28.1(-50.8,-5.3)^{\star}$ \\
\hline No education completed & $-4.6(-11.4,2.2)$ & $-14.9(-24.8,-5.0)^{\star}$ & $-26.4(-48.6,-4.2)^{\star}$ \\
\hline \multicolumn{4}{|l|}{ Mental health } \\
\hline Whole population & $73.7(0.5)$ & $67.9(0.6)$ & $64.8(0.7)$ \\
\hline Third level & $78.8(0.9)$ & $70.6(1.9)$ & $69.3(4.2)$ \\
\hline Second level & $-4.7(-7.6,-1.7)^{\star}$ & $2.1(-4.2,8.7)$ & $0.6(-11.7,13.0)$ \\
\hline First level & $-10.2(-13.8,-6.6)^{\star}$ & $-2.9(-9.0,3.2)$ & $-4.4(-16.1,7.3)$ \\
\hline No education completed & $-9.7(-14.3,-5.1)^{\star}$ & $-6.7(-12.9,-0.6)^{\star}$ & $-5.6(-17.0,5.8)$ \\
\hline
\end{tabular}

† Difference between the mean rating at each educational level and the rating of the group with the third level education. ${ }^{\star}$ Statistically significant difference $(p<0.05)$.

was slightly larger than in the general population $(18 \%)$. This study has been limited to the population of persons aged 25 or older.

THE SF-36 HEALTH SURVEY

The SF-36 is a generic instrument containing 36 items covering eight dimensions of perceived health: general health perceptions (5 items), physical functioning (10 items), role limitations because of physical functioning (4 items), bodily pain (2 items), general mental health (5 items), role limitations because of emotional problems (3 items), vitality (4 items), and social functioning (2 items). The remaining item, relating to change in health, is not scored as a separate dimension. The items detect both positive and negative states of functional status, well being and an "overall evolution of health" ${ }^{11}{ }^{17}$

For each dimension of the SF-36, the items were coded, aggregated, and transformed on a scale ranging from 0 (the worst health status) to 100 (the best health status), as described in the scoring manual. ${ }^{18}$ An algorithm was

Table 4 Mean increase (95\% CI) in the value of each dimension associated with one year additional education, adjusted by marital and occupational status

\begin{tabular}{|c|c|c|c|c|c|c|}
\hline & \multicolumn{3}{|l|}{ Men } & \multicolumn{3}{|l|}{ Women } \\
\hline & $25-44$ & $45-64$ & $65+$ & $25-44$ & $45-64$ & $65+$ \\
\hline Physical functioning & $0.10(-0.03,0.24)$ & $0.79(0.52,1.05)$ & $1.89(1.42,2.36)$ & $0.24(0.08,0.41)$ & $1.54(1.22,1.86)$ & $2.05(1.46,2.64)$ \\
\hline Role physical & $0.24(-0.03,0.52)$ & $1.2390 .78,1.68)$ & $2.20(1.51,2.89)$ & $1.12(-0.23,0.49)$ & $1.19(0.64,1.74)$ & $2.05(1.08,3.01)$ \\
\hline Bodily pain & $0.25(0.12,0.49)$ & $1.01(0.64,1.38)$ & $1.17(0.69,1.65)$ & $0.43(0.13,0.72)$ & $1.04(0.60,1.47)$ & $1.68(1.01,2.36)$ \\
\hline General health & $0.53(0.33,0.72)$ & $1.04(0.77,1.31)$ & $1.45(1.06,1.84)$ & $0.68(0.48,0.88)$ & $1.38(1.07,1.68)$ & $1.55(1.06,2.03)$ \\
\hline Vitality & $0.18(-0.01,0.39)$ & $0.68(0.38,0.99)$ & $1.68(1.29,2.08)$ & $0.47(0.24,0.71)$ & $0.92(0.60,1.23)$ & $1.13(0.64,1.61)$ \\
\hline Social fuctioning & $0.13(-0.01,0.27)$ & $0.53(0.30,0.77)$ & $1.08(0.66,1.50)$ & $0.24(0.04,0.44)$ & $0.53(0.21,0.85)$ & $1.21(0.64,1.78)$ \\
\hline Role emotional & $0.26(0.05,0.48)$ & $0.63(0.31,0.96)$ & $1.18(0.64,1.72)$ & $0.36(0.03,0.69)$ & $1.21(0.71,1.71)$ & $1.45(0.56,2.35)$ \\
\hline Mental health & $0.43(0.24,0.62)$ & $0.70(0.44,0.95)$ & $0.97(0.60,1.33)$ & $0.83(0.60,1.05)$ & $0.79(0.48,1.10)$ & $0.85(0.40,1.31)$ \\
\hline
\end{tabular}



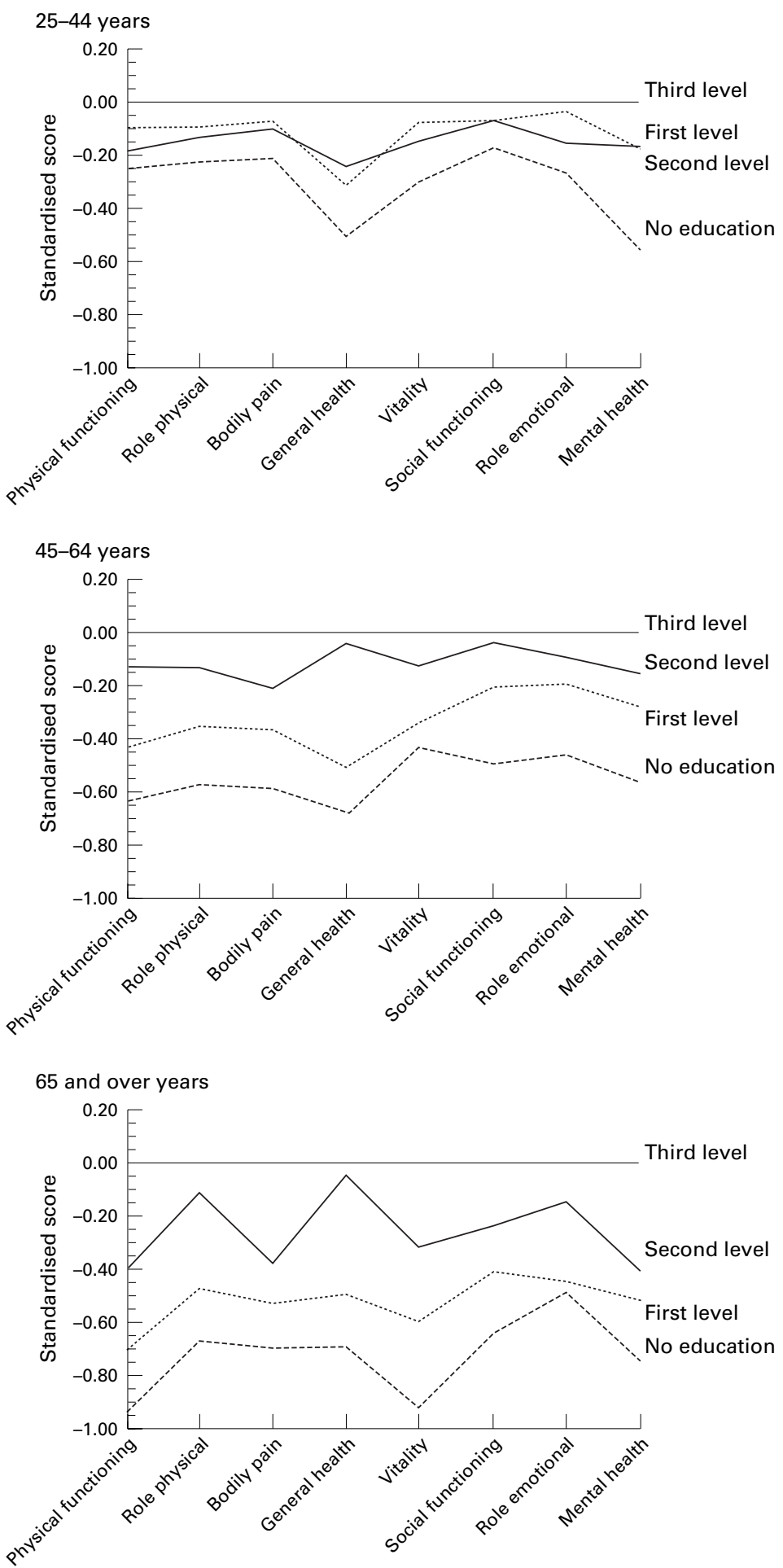

Figure 1 Standardised differences in mean ratings on the SF-36 between the group with the third level education and the other educational level groups, by age group for men.

executed to impute missing information whenever there was information for at least half of the items of the dimension. ${ }^{17}$

ANALYSIS

The persons interviewed were shown a card containing a classification with nine educational levels, and they were asked which was the highest educational level they had attained. Based on the answers given to this question, the persons were divided into four groups depending on the level attained: no education completed, first level education, second level education, and third level education. Differences in the mean ratings on each dimension in each group were analysed in men and women with respect to the group with third level education, which was taken as the reference group. To assess the association between educational level and age the present analysis was made in three age groups: 25-44 years, 45-64 years, and 65 years and older. The internal consistency of the different dimensions of the SF-36 Health Questionnaire in these age groups was acceptable. All values of Cronbach's alpha were above 0.7 , except for the vitality dimension in men aged 25-34 years, which had a value of 0.69 .

The results are presented as absolute differences and as standardised differences. Absolute differences make it possible to compare the health of different groups with regard to the reference group. The statistical significance of these differences was measured using Student's $t$ test. Because multiple comparisons were made, we used Bonferroni's method to guarantee a type 1 error of 0.05 for the entire set of comparisons.

Ordinary least squares regression was also used to evaluate the effect of education on each dimension, adjusted for marital status and occupation in each age and sex group. Each of the nine educational levels on the questionnaire was previously assigned a mean number of years of education. The effect of education is thus expressed as a mean increase in the score of each dimension for each additional year of education.

The standardised differences were calculated by dividing the absolute differences by the standard deviation of the whole population. This is known as the effect size. ${ }^{19}$ It has been suggested that an effect size of 0.2 reflects small differences in health status, a value of 0.5 , moderate differences, and a value of 0.8 , large differences. ${ }^{20}$ The results obtained are presented graphically, making it possible to compare the health of educational level groups with respect to the reference group across each dimension of the SF-36 Health Survey.

\section{Results}

Table 1 shows the number of men and women analysed, distributed by age and educational level. Tables 2 and 3 show the mean scores in each dimension of the SF-36 Health Survey for men and women, respectively, and for each age group studied, for the whole population and for persons with third level education (the reference group). It also shows the absolute differences between the mean ratings of the rest of the educational level groups and the reference group.

In general, perceived health status declined with decreasing educational level, so that the lowest scores were found in persons with the least education. The exception to this rule is some dimensions in women; specifically, women with second level education showed higher scores than women with third level edu- 

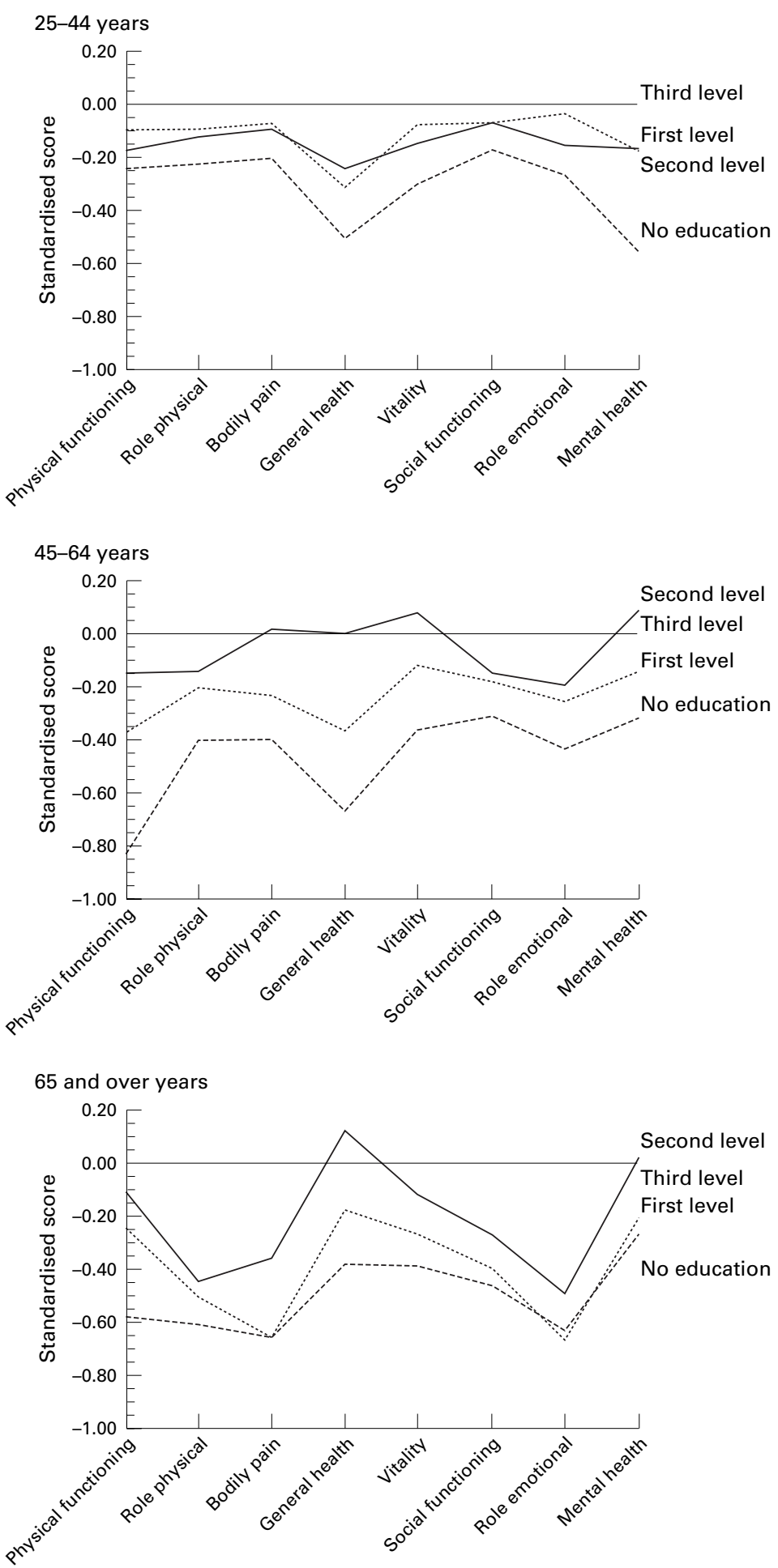

Figure 2 Standardised differences in mean ratings on the SF-36 between the group with the third level education and the other educational level groups, by age group for women.

cation in physical function, physical role, and social function in the 25-44 year age group, in general health and mental health in those older than 45 , and in vitality in those $45-64$ years of age.

In men, statistically significant differences in all health dimensions were found in the 45-64 and the 65 and over age groups-mainly in persons with first level education and in those with no education completed. In women,
KEY POINTS

- The lowest ratings on the dimensions of the SF-36 Health Questionnaire are found among persons with the lowest educational level.

- In men, the highest ratings on the dimensions of the SF-36 Health Questionnaire are found among those with third level education, whereas in women the highest ratings on several dimensions are found among those with second level education.

- In men, the absolute differences in perceived health by educational level increase with age, however this phenomenon is not found in women for all dimensions.

statistically significant differences were also found in these age groups-mainly in those with no education-except for the dimensions of general health, vitality, social function, and general health in those 65 and over. In the 25-44 year age group, statistically significant differences were found for only some health dimensions, in both men and women.

On the other hand, differences in perceived health between the different educational level categories and the reference category become larger with increasing age, although among women this phenomenon was not seen for physical function, general health or metal health. Likewise, table 4 shows that the mean increase in the score of each dimension associated with one additional year of education is larger with increasing age.

Figures 1 and 2 show the standardised differences between the ratings of each group and the rating of the reference group. These figures reproduce the results observed in tables 2 and 3; they also allow comparisons among the different dimensions. Thus, it can be seen that the largest differences in persons 25-44 years of age are produced in mental health and general health, in both men and women. In the 45-64 year age group, the largest differences are seen in physical function and general health, in both men and women; and in the 65 and over age group, the largest differences are seen in physical function and vitality in men, and in bodily pain and emotional role in women.

\section{Discussion}

The results of this study show that, in general, persons with a high educational level-third level - rate their health status higher than persons with a low educational level-no education completed or first level education. In all the groups analysed the mean score in all the dimensions of the Health Survey was lower in persons with no education than in those with third level education. Likewise, in general, it is seen that the mean rating on any dimension is lower in persons with no education than in those with first level education, lower in persons with first level than in those with second level and, in turn, lower in persons with second level than in those with third level edu- 
cation. These results are in good agreement with findings in the history of public health research, that is, that the lower socioeconomic strata are associated with lower health status, ${ }^{1-6}$ and that there is no threshold above which persons are safe from health problems; rather, the relation between socioeconomic level and health is linear. ${ }^{51}$

Exceptions to this general pattern are seen in some dimensions in women. For example, in general health and mental health, beginning at age 45 , women with second level education have a higher rating than women with third level education. Although the differences were not statistically significant, probably because of small numbers, they may be related with a higher frequency of health problems among women with third level education than in those with second level education; specifically, in the 1993 National Health Survey in Spain, women older than 45 with third level education reported a greater frequency of chronic diseases than women with second level education. ${ }^{22}$ A recent study has also shown that female professionals and managers report more physical symptoms than other working women. ${ }^{23}$ Likewise, in the first cross sectional study made with data from the Whitehall II Study it was seen that women 35 to 55 years of age with the highest employment level had poorer self reported health than women with intermediate occupations on the hierarchical scale. ${ }^{24}$ The authors point out that for women there may be more health selection into employment than there is for men, making measures of current occupational status less adequate for describing the socioeconomic status gradient in health for women. However, this is not the best explanation for our study as it includes all women-both those with and without paid work. Furthermore, curiously, in a nationally representative British sample of men and women aged 36 years, women with higher education were not in the best health group either. ${ }^{25}$ To the authors it was unclear whether these women had a higher tendency to report minor or moderate health problems than less educated female peers or whether the prevalence of at least one problem was indeed more common.

Our results may very well be because of a cohort effect, as the few Spanish women with university education at that age $(2.5 \%$ according to the last census in 1991) have had a greater lifetime exposure to stressful life events than women with second level education. The effort required to compete in an occupational sector dominated by men, in addition to responsibility for household domestic chores at a time when family responsibilities were assumed exclusively by women, could explain this greater exposure to risk factors of a psychosocial nature. It has been hypothesised that the difficulties faced by women in confronting the multiple demands and conflicts derived from their role as mothers and workers may be prejudicial to their health. ${ }^{26}$ However, it is not known why Spanish women 25-44 years of age with second level education have a better rating than women with third level education in physical function and social function.

Another finding of this study is that the health dimensions with the greatest differences by educational level vary with age. Thus, in the 25-44 year age group the largest differences are seen in mental health and general health, in both men and women. It is quite possible that the low frequency of physical health problems in this age group limits the possibility of finding differences in dimensions other those related with mental health. It is also possible that at this age persons with fewer educational or material resources have not yet acquired the skills and abilities necessary to reduce the mental health impact of certain family, social and work related events. The differences in perceived general health probably merely reflect these differences in mental health.

On the other hand, in the 45-64 year age group, the largest differences are observed in physical function as well as general health. At this age certain health problems begin to appear that mainly affect physical function, such as heart and respiratory diseases. ${ }^{27}$ The prevalence of these diseases is higher in persons in the lower socioeconomic strata, which may explain why the differences by educational level are larger on this dimension. Thus, the differences in perceived general health would only be reflecting this greater frequency of health problems in individuals with lower educational level.

In men 65 and over, physical function is still the dimension with the largest differences by educational level, while in women in this age group the largest differences are in bodily pain. These results are especially important given the high frequency of diseases and health problems that cause disability in this age group, especially in women. One possible explanation for this finding could be that women with a lower educational level rate the pain resulting from these health problems as more important in their lives than the functional disability they produce.

The third outstanding finding of this study is that the association between all SF-36 dimension scores and educational level is highest in persons 65 and older and lowest in persons aged 25-44, except among women for physical function, general health, and mental health. This result stands in contrast with the empirical evidence showing that the relative differences in health by educational level decrease with age. ${ }^{28-30}$ The explanation for this increase in absolute differences with age can be attributed to the influence of the magnitude of health problems in this measure. Most of the less healthy persons in the lower socioeconomic levels probably become ill or die while they are young adults, while less healthy persons in the higher socioeconomic levels survive because of better social and economic conditions. $^{28} 2931$ This is why the relative differences are very large in this period; in contrast, given the small magnitude of health problems, the absolute differences are low. Beginning at this age, because of this selective survival proc- 
ess, the proportional growth in the frequency of health problems in persons with low educational level is less than in those with high educational level, causing the relative differences to decrease; in contrast, as the frequency of health problems increases, the absolute differences also rise.

However, this explanation may very well not apply to women because in persons aged 65 and older the absolute differences by educational level in some dimensions are less than in younger age groups. These results probably reflect a low health status in women with third level education in that age group because of their accumulated exposure to psychosocial risk factors, as mentioned earlier. However, as these results affect only certain dimensions, it may also be that the SF-36 Health Survey is limited in the extent to which it can detect some health dimensions in elderly women, such as physical functioning, general health, and mental health.

In interpreting these results, some considerations with regard to the sample design should also be kept in mind. For example, it is quite possible that people with no education completed are over-represented in the final sample because the interviewers were more likely to find them at home than other population groups. If they were at home because of health related problems, the differences observed with respect to persons with third level education would be overestimated. It should also be noted that the failure to find any statistically significant differences in many dimensions in women over 65 years of age may be because of the small sample size of women with third level education. Finally, it should be noted that, although we are dealing with a noninstitutionalised population, the influence that this may have had on the results is unknown because we do not know if the rate of institutionalisation in persons over 65 years of age varies by educational level.

Finally, mention should be made of the difficulty of analysing changing trends in population health status using the SF-36 Health Survey because it is possible that any change will be very small in heterogeneous population samples and, therefore, the effect size will be barely perceptible. ${ }^{32}$ However, Jenkinson has pointed out that the SF-36 is sensitive to social variations in health and that it can detect changes at the population level as long as they are analysed in those population groups with the poorest health. ${ }^{33}$ This author tested his hypothesis by evaluating the differences between people in the 25 th percentile on each dimension in social classes I and V. Similarly, the relatively high frequency of health problems in the groups used in our study makes it possible to detect changes in their health status, particularly in the age groups 45-64 years and in those over 64 , in whom effect sizes higher than 0.2 have generally been shown.

Some authors have criticised the use of generic indicators of health status, based on instruments to measure quality of life, as a means for assigning health service resources because such instruments do not give information about specific health problems. ${ }^{32} 34$ However, although it is essential to determine the health resources needed for particular interventions to alleviate and mitigate many forms of morbidity, consideration of medical interventions alone does not take account of either the socioeconomic determinants of health and illness or alternative interventions aimed at those determinants. Thus, it may be very useful to monitor differences in various health dimensions by socioeconomic level to demonstrate the need to implement certain economic and social interventions and to evaluate the overall health impact of some of these interventions. The same as with economic indicators, policy makers and planners in the health arena should support and stimulate initiatives aimed at increasing health overall, and not only those dimensions most closely related with the provision of health services.

Funding: none.

Conficts of interst: none.

1 Marmot MG, Shipley MJ, Rose G. Inequalities in death specific explanations of a general pattern. Lancet 1984;i:1003-6.

2 Feldman J, Makuc DM, Kleinman JC, et al. National trends in educational differentials in mortality. Am $\mathcal{F}$ Epidemiol in educational differ

3 Marmot MG, Davey Smith G, Stansfeld S, et al. Health inequalities among British civil servants: the Whitehall II study. Lancet 1991;337:1387-93.

4 Feinstein JS. The relation between socio-economic status and health: a review of the literature. Milbank $Q$ 1993;71:279-322.

5 Adler NE, Boyce WT, Chesney MA, et al. Socio-economic inequalities in health. $7 A M A$ 1993;269:3140-5.

6 Mackenbach JP, Kunst AE, Cavelaars AEJM, et al, EU Working Group on Socioeconomic Inequalities in Health. Socioeconomic inequalities in morbidity and mortality in Western Europe. Lancet 1997;349:1655-9.

7 Syme SL. Social determinants of disease. In: Last JM, Wallace RB, eds. Public health and preventive medicine. 13th ed. Connecticut: Prentice Hall International, 1992:687-700.

8 Syme SL. Rethinking disease: where do we go from here? Ann Epidemiol 1996;6:463-8.

9 Hunt SM, Mckenna SP, McEwen J, et al. A quantitative approach to perceived health status: a validation study. $\mathcal{f}$ Epidemiol Community Health 1980;34:281-6.

10 Bergner M, Bobbit RA, Pollard WE, et al. The Sickness Impact Profile: development and final revision of a health status measure. Med Care 1981;19:787-805

11 Ware JE, Sherbourne CD. The MOS 36-item short-form health survey (SF-36): I. Conceptual framework and item selection. Med Care 1992;30:473-83.

12 Hennessy CH, Moriarty DG, Zack MM, et al. Measuring health-related quality of life for public health surveillance. Public Health Rep 1994;109:665-72.

13 Instituto Nacional de Estadistica. Encuesta de Poblacion Activa. Tablas Anuales 1995. Madrid: INE, 1996.

14 Krieger N, Williams DR, Moss NE. Measuring social class in US public health research: concepts, methodologies, and guidelines. Annu Rev Public Health 1997;18:341-78.

15 Alonso J, Prieto L, Anto JM. La version española del SF-36 Health Survey (Cuestionario de Salud SF-36): un instruHealth Survey (Cuestionario de Salud SF-36): un instru-
mento para la medida de los resultados clRnicos. Med Clin (Barc) 1995;104:771-6.

16 Alonso J, Regidor E, Barrio L, et al. Valores poblacionales de referencia de la version española del Cuestionario de Salud SF-36. Med Clin (Barc) (in press).

17 Ware JE, Kosisnski M, Keller SD. SF-36 Physical and mental health summary scales: a user's manual. Boston, MA: The Health Institute, New England Medical Center, 1994

18 Medical Outcomes Trust. Puntuacion del Cuestionario de Salud SF-36. Version Española (España). Boston, MA: Medical Outcomes Trust, 1996.

19 Cohen J. Statistical power analysis for the behavioral sciences. Hillsdale, New Jersey: Lawrence Elrbaum Associates, 1988.

20 Kazis LE, Anderson JJ, Meenan RF. Effect sizes for interpreting changes in health status. Med Care 1989;27 (suppl 3):S178-89.

21 Macintyre S. Understanding the social patterning of health: the role of the social sciences. F Public Health Med 1994;16: 53-9.

22 Regidor E, Gutierrez-Fisac JL, Rodriguez C, et al. La desigualdad social y la salud en España. In: Navarro C, 
Cabases JM, Tormo MJ. La salud y el sistema sanitario. Informe SESPAS 1995. Barcelona: SG Editores, 1995:19-43. 23 Bartley M, Popay J, Pewis I. Domestic conditions, paid Bartley M, Popay J, Pewis I. Domestic conditions, paid employment and women's experience

24 Marmot M, Ryff CD, Bumpass LL, et al. Social inequalities in health: next questions and converging evidence. Soc Sci Med 1997;44:901-10

25 Kuh DJL, Wadsworth MEJ. Physical health status at 36 years in a British national birth cohort. Soc Sci Med 1993; 37:905-16.

26 Weatherall R, Joshi H, Macran S. Double burden or double blessing? Employment, motherhood and mortality in the longitudinal study of England and Wales. Soc Sci Med 1994;38:285-97.

27 Stewart AL, Greenfield S, Hays RD, et al. Funcional status and well-being of patients with chronic conditions. $\mathcal{F} A M A$ 1989;262:907-13

28 House JS, Kessler RC, Herzog R, et al. Age, socio-economic status, and health. Milbank Q 1990;68:383-411.
29 Idler EL. Age differences in self-assessment of health: age changes, cohort differences, or survivorship? f Gerontal changes, cohort differ

30 Reijneveld SA, Gunning-Schepers LJ. Age, health and measurement of the socio-economic status of individuals. Eur f Public Health 1995;5:187-92.

31 Jefferys $M$. Social inequalities in health - Do they diminish with age? Am f Public Health 1996;86:474-5.

32 Ziebland S. The short form 36 health status questionnaire: clues from the Oxford region's normative data about its usefulness in measuring health gain in population surveys. 7 Epidemiol Community Health 1995;49:102-5.

33 Jenkinson C, Layte R, Coulter A, et al. Evidence for the sensitivity of the SF-36 health status measure to inequalities in health: results from the Oxford healthy lifestyles survey. $\mathcal{F}$ Epidemiol Community Health 1996;50:377-80.

34 Donovan JL, Frankel SJ, Eyles JD. Assessing the need for health status measures. $\mathcal{f}$ Epidemiol Community Health 1993;47:158-62.

\section{$\mathrm{JECH}$ and the world wide web}

Visitors to the world wide web can now access the fournal of Epidemiology and Community Health either through the BMJ Publishing Group's home page (http://www.bmjpg.com) or directly by using its individual URI (http://www.jech.com). There they will find the following:

- Current contents list for the journal

- Contents lists of previous issues

- Members of the editorial board

- Subscribers' information

- Instructions for authors

- Details of reprint services.

\section{Hotlink}

A hot link gives access to:

- BMJ Publishing Group home page

- British Medical Association website

- Online books catalogue

- BMJ Publishing Group books.

\section{Suggestions welcome}

The website is at a preliminary stage and there are plans to develop it into a more sophisticated site. Suggestions from visitors about features they would like to see are welcomed. They can be left via the opening page of the BMJ Publishing Group site or, alternatively, via the journal page, through "about this site". 